\title{
Endovascular Treatment of Vein of Galen Malformations: A Systematic Review and Meta-Analysis
}

\author{
(D)W. Brinjikji, (D)T. Krings, (D) M.H. Murad, (D)A. Rouchaud, and (DD. Meila
}

\begin{abstract}
BACKGROUND: Outcomes after endovascular embolization of vein of Galen malformations remain relatively poorly described.

PURPOSE: We performed a systematic review of the literature to determine outcomes and predictors of good outcomes following endovascular treatment of vein of Galen malformations.
\end{abstract}

DATA SOURCES: We used Ovid MEDLINE, Ovid Embase, and the Web of Science.

STUDY SELECTION: Our study consisted of all case series with $\geq 4$ patients receiving endovascular treatment of vein of Galen malformations published through January 2017.

DATA ANALYSIS: We studied the following outcomes: complete/near-complete occlusion rates, technical complications, perioperative stroke, perioperative hemorrhage, technical mortality, all-cause mortality, poor neurologic outcomes, and good neurologic outcomes. Outcomes were stratified by age-group (neonate, infant, child). A random-effects meta-analysis was performed.

DATA SYNTHESIS: A total of 27 series with 578 patients were included; $41.9 \%$ of patients were neonates, $45.0 \%$ of patients were infants, and $13.1 \%$ of patients were children. All-cause mortality was $14.0 \%(95 \% \mathrm{Cl}, 8.0 \%-22.0 \%)$. Overall good neurologic outcome rates were $62.0 \%$ (95\% Cl, 57.0\%-67.0\%). Overall poor neurologic outcome rates were $21.0 \%$ (95\% Cl, $17.0 \%-26.0 \%)$. Neonates were significantly less likely to have good neurologic outcomes than infants (48.0\%; $95 \% \mathrm{Cl}, 35.0 \%-62.0 \%$ versus $77.0 \% ; 95 \% \mathrm{Cl}, 70.0 \%-84.0 \% ; P<.01$ ). Treatment indications following the Bicêtre neonatal evaluation score resulted in significantly higher rates of good neurologic outcome $(P=.04)$. Patients with congestive heart failure had significantly lower rates of good neurologic outcome (OR, $0.50 ; 95 \% \mathrm{Cl}, 0.28-0.88 ; P=.01)$.

LIMITATIONS: Limitations were selection and publication biases.

CONCLUSIONS: Patients receiving endovascular embolization of vein of Galen malformations experienced good long-term clinical outcomes in $>60 \%$ of cases. Appropriate patient selection is key as treatment guided by the Bicêtre neonatal evaluation score was associated with improved neurologic outcomes.

ABBREVIATIONS: BNES = Bicêtre neonatal evaluation score; $\mathrm{CHF}=$ congestive heart failure; PRISMA = Preferred Reporting Items for Systematic Reviews and Meta-Analyses; VOGM = vein of Galen arteriovenous malformation

V ein of Galen arteriovenous malformations (VOGMs) are shunts that form in utero between the choroidal arteries and the precursor of the vein of Galen, the median prosencephalic vein of Markowski. ${ }^{1-3}$ Current prevalence estimates of VOGM are quite low, often cited at $<1$ of 25,000 deliveries. ${ }^{4,5}$ A number of

Received June 14, 2017; accepted after revision August 7.

From the Departments of Radiology (W.B.), Neurosurgery, (W.B.) and Center for the Science of Healthcare Delivery (M.H.M.), Mayo Clinic, Rochester, Minnesota; Division of Neuroradiology and Neurosurgery (W.B., T.K.), University of Toronto, Toronto Western Hospital and University Health Network, Toronto, Ontario, Canada; Neuroradiology Service (A.R.), Centre Hospitalier Universitaire Bicêtre, Le Kremlin Bicêtre, France; Department of Radiology and Neuroradiology (D.M.), Klinikum Duisburg, Duisburg, Germany; and Department of Diagnostic and Interventional Neuroradiology (D.M.), Medical School Hannover, Hannover, Germany. studies have shown that the natural history of VOGMs is very poor, with many patients succumbing to complications related to congestive heart failure (CHF), hydrocephalus, and brain parenchymal injury.

Endovascular embolization of VOGMs has emerged as a standard of care in this patient population; however, long-term outcomes after endovascular embolization, as well as predictors of good neurologic outcomes, are still poorly understood. ${ }^{2-4,6-47}$

Please address correspondence to Waleed Brinjikji, MD, Mayo Clinic, 200 First St SW, Rochester, MN 55905; e-mail: brinjikji.waleed@mayo.edu; brinjikji.waleed@gmail.com; @wbrinjikji

三 Indicates article with supplemental on-line tables.

http://dx.doi.org/10.3174/ajnr.A5403 
Thus, to assess the status of endovascular treatment for VOGMs, we performed a systematic review and meta-analysis with an emphasis on determining factors associated with good neurologic outcome in this patient population.

\section{MATERIALS AND METHODS Literature Search}

Our study adheres to Preferred Reporting Items for Systematic Reviews and Meta-Analyses (PRISMA; http://prisma-statement. org/) guidelines. To identify studies on outcomes of endovascular treatment of VOGMs, we performed a computerized MEDLINE search of the literature from January 1980 to January 2017. Three data bases were searched from January 1980 to April 2017: Ovid MEDLINE, Ovid Embase, and the Web of Science as described in On-line Table 1. Initial search terms included "Vein of Galen," "malformation," "aneurysm," “endovascular," “coil," "embolization," and "occlusion." Identified studies from the search were then further evaluated for inclusion in the systematic review. Inclusion criteria were the following: 1) studies reporting a consecutive series of endovascular treatment of VOGMs ( $\geq 4$ patients), including case series and clinical trials; and 2) studies reporting angiographic and/or clinical outcomes following treatment. Case reports were excluded from this study. Two independent reviewers selected studies for this analysis.

\section{Data Extraction and Outcomes}

Each study was analyzed by 2 independent reviewers to collect the following data: 1) patient presentation (congestive heart failure, hydrocephalus, seizure); 2) patient demographics (age, sex); 3 ) treatment type (transarterial versus transvenous); 4) number of treatments/stages; 5) perioperative complications (technical mortality, perioperative ischemia, and perioperative hemorrhage); 6) complete/near-complete embolization rate; 7) long-term clinical outcomes, including good clinical outcome (defined as no or minor developmental delay and no permanent disability), poor clinical outcome, and all-cause mortality; and 8) angioarchitecture of the lesion (mural versus choroidal). The primary outcome of this study was good neurologic outcome rates. Good neurologic outcome was defined as a child with normal development.

In addition to determining overall rates of the outcomes listed above, we performed subgroup analyses dividing patients by age group. The 3 age groups studied were neonates (younger than 1 month of age), infants ( 1 month to 2 years of age), and children (2 years of age and older). We also performed subgroup analyses to determine whether the following variables were associated with rates of good neurologic outcome: 1) use of the Bicêtre neonatal evaluation score (BNES) for patient selection, 2) the presence of $\mathrm{CHF}, 3$ ) a prenatal diagnosis of VOGM, 4) hydrocephalus, and 5) type of VOGM (mural versus choroidal). A subgroup analysis by follow-up time ( $\leq 2$ years versus $>2$ years) was also performed.

\section{Risk of Bias Assessment}

Risk of bias assessment of the studies was performed with a modified Newcastle-Ottawa Scale. This tool is used for assessing the quality of nonrandomized studies included in systematic reviews and/or meta-analyses. Each study is judged on 8 items categorized into 3 groups: 1) selection of the study groups, 2) comparability of

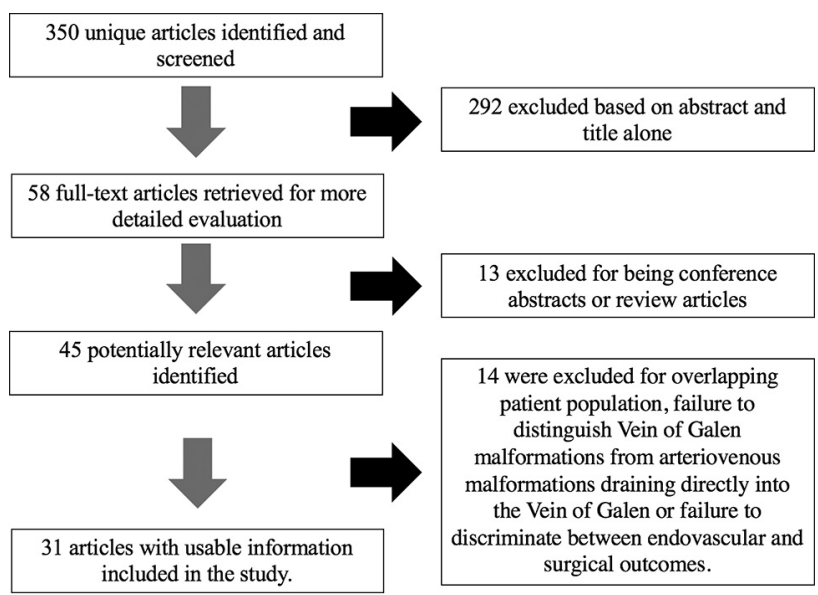

FIG 1. PRISMA flow diagram.

the study groups, and 3) ascertainment of the outcome of interest. ${ }^{48}$ Factors that would make a study at low risk of bias would include the following: 1) well-defined selection criteria, 2) welldefined treatment regimen, 3) rates of long-term follow-up of $>90 \%$ for surviving patients, and 4) age-based stratification of outcomes.

\section{Statistical Analysis}

We estimated, from each study, the cumulative incidence (event rate) and 95\% confidence interval for each outcome. Event rates were pooled across studies with a random-effects meta-analysis. ${ }^{49}$ Heterogeneity across studies was evaluated with the $I^{2}$ statistic. $^{50}$ Analysis of outcomes for children older than 2 years of age could not be performed due to the lack of sufficient studies. Analysis was conducted with STATA Statistical Software, Release 14 (StataCorp, College Station, Texas).

\section{RESULTS}

\section{Literature Search, Study Characteristics, and Risk of Bias}

The initial literature searched yielded 350 unique articles. On review of the abstracts and titles, 292 articles were immediately excluded. Fifty-eight articles were retrieved for full-text evaluation. Of these, 13 were excluded because they were review articles or conference abstracts with insufficent information. Forty-five articles were then evaluated. Of these, 14 were excluded for overlapping patient populations, failure to distinguish vein of Galen malformations from arteriovenous malformations draining directly into the vein of Galen, or failure to discriminate between endovascular and surgical outcomes. In total, 31 articles reflective of the experiences of 27 centers were included. There were 4 articles that had overlapping patient populations, but these were included because they provided additional data not available in other articles from the institution. In total, 578 unique patients were included. These findings are summarized in Fig 1.

Six institution experiences were found to have a low risk of bias, 7 institution experiences had a moderate risk of bias, and 14 studies had a high risk of bias. Eight institution experiences used the BNES in determining patient eligibility for treatment. The number of patients ranged from 4 to 216 . Mean follow-up ranged from 0.5 to 6.8 years with a median of 2 years. These data are summarized in On-line Table 2.

AJNR Am J Neuroradiol 38:2308-14 Dec 2017 www.ajnr.org 


\section{Baseline Characteristics and Patient Presentation}

The median age of patients included in this study was 0.1 month. Age data were available for 547 patients; 229 patients were neonates (41.9\%), 246 patients were infants (45.0\%), and 72 patients were children (13.2\%). Sex data were available for 252 patients, and 173 patients $(68.7 \%)$ were male. Patient presentation data were available for 318 patients. The most common presentation was CHF (201 patients, 63.2\%), followed by hydrocephalus (86 patients, $27.0 \%$ ) and seizure (37 patients, $11.6 \%$ ). Intracranial hemorrhage was present in 26 patients $(8.2 \%)$. An age-related breakdown of patient presentation is provided in Fig 2. Briefly, the most common presentation in neonates was CHF (88.2\%). The most common presentation in infants and children was increased head circumference ( $53.3 \%$ and $37.5 \%$, respectively). Angioarchitectural characteristics were available for 276 patients, with 103 being mural (37.3\%) and 173 being choroidal (62.7\%).

\section{Angiographic Outcomes}

Twelve studies primarily used transarterial embolization for treatment of VOGMs. The median number of treatments ranged from 1.5 to 4.1 , with the overall median of included studies being $2.25 ; 27.9 \%$ of patients received 1 treatment, $29.1 \%$ received 2 treatments, and $43.0 \%$ received $\geq 3$ treatments. The overall complete occlusion rate was $56.0 \%$ (95\% CI, 46.0\%-66.0\%), with no difference between neonates and infants.

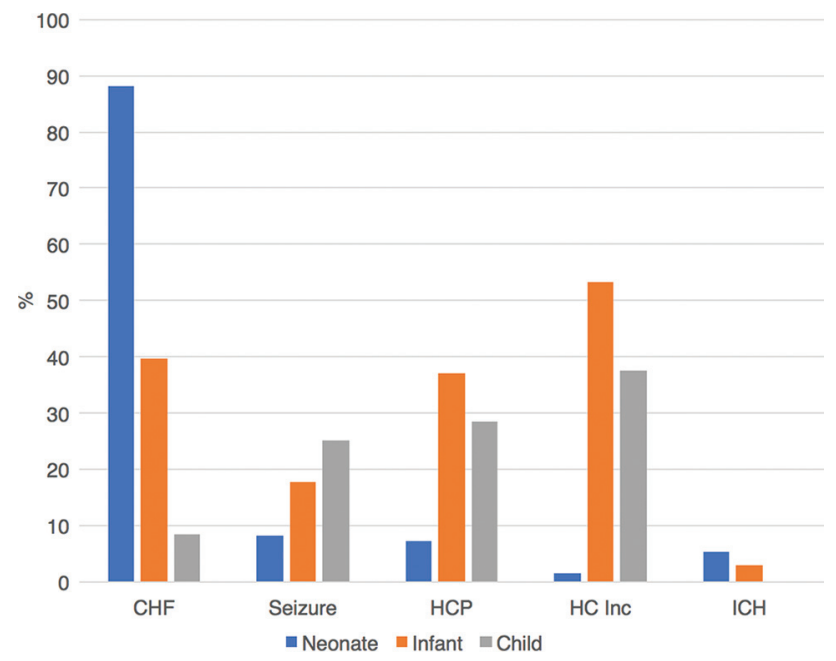

FIG 2. Presentation by age group. HCP indicates hydrocephalus; HC, head circumference; ICH, intracranial hemorrhage; inc, increase.

\section{Perioperative Complications}

The overall technical complication rate was $19.0 \%$ (95\% CI, $12.0 \%-27.0 \%$ ), with a trend toward a significantly higher rate of technical complications among neonates $(29.0 \%$; 95\% CI, $17.0 \%-41.0 \%)$ compared with infants $(10.0 \%$; $95 \%$ CI, $0.0 \%-$ $27.0 \% ; P=.07)$. Overall perioperative hemorrhage rates were 9.0\% (95\% CI, 4.0\%-15.0\%), with no difference between age groups $(P=.25)$. Overall perioperative ischemia rates were $1.0 \%$ $(95 \% \mathrm{CI}, 0.0 \%-2.0 \%)$, with a higher rate among neonates $(3.0 \%$; $95 \% \mathrm{CI}, 0.0 \%-10.0 \%)$ compared with infants $(0.0 \%$; $95 \% \mathrm{CI}$, $0.0 \%-2.0 \% ; P=.03)$. Non-neurologic complicate rates were $2.0 \%$ (95\% CI, $0.0 \%-4.0 \%$ ), with no difference among groups $(P=1.0)$. The overall technical mortality rate was $1.0 \%(95 \% \mathrm{CI}$, $0.0 \%-5.0 \%)$, with higher rates in neonates $(2.0 \%$; $95 \% \mathrm{CI}, 0.0 \%-$ $8.0 \%)$ than in infants $(0.0 \% ; 95 \% \mathrm{CI}, 0.0 \%-2.0 \% ; P=.03)$. These data are summarized in the Table.

\section{Long-Term Outcomes}

The overall rate of good neurologic outcome was $62.0 \%$ (95\% CI, $57.0 \%-67.0 \%)$. Neonates had significantly lower rates of good neurologic outcomes (48.0\%; 95\% CI, 35.0\%-62.0\%) compared with infants (77.0\%; 95\% CI, 70.0\%-84.0\%; $P<.0001)$. Overall rates of poor neurologic outcome were $21.0 \%$ (95\% CI, $17.0 \%$ $26.0 \%)$, with higher rates among neonates $(22.0 \%$; $95 \% \mathrm{CI}$, $15.0 \%-31.0 \%)$ compared with infants $(16.0 \%$; $95 \%$ CI, $10.0 \%-$ $23.0 \% ; P=.01)$. The all-cause mortality rate was $14.0 \%$ (95\% CI, $8.0 \%-20.0 \%)$, with significantly higher rates among neonates (27.0\%; 95\% CI, $15.0 \%-41.0 \%)$ compared with infants $(1.0 \%$; $95 \%$ CI, $0.0 \%-4.0 \% ; P<.0001)$. These data are summarized in the Table. The forest plot for good neurologic outcomes is provided in Fig 3.

\section{Follow-Up Time, Patient Selection, and Baseline Characteristics and Outcomes}

Seven studies reported the use of the BNES in selecting patients for treatment of VOGMs. Studies that reported the use of the BNES had significantly higher rates of good neurologic outcome than those that did not $(62 \%$; $95 \%$ CI, $50.0 \%-72.0 \%$ versus $57 \%$; 95\% CI, 51.0\%-65.0\%; $P=.04)$.

Patients with CHF were significantly less likely to experience good neurologic outcomes than those without CHF (49.4\%; 95\% CI, 21.7\%-57.1\% versus 66.2\%; 95\% CI, 55.1\%-75.8\%; $P=.01$ ). Patients with hydrocephalus (61.0\%; 95\% CI, 45.7\%-74.4\%) had similar rates of good neurologic outcome as those without it (62.0\%; 95\% CI, 53.4\%-70.0\%; $P=.92)$. Patients with mural-

Systematic review outcomes

\begin{tabular}{|c|c|c|c|c|c|c|c|}
\hline & $\begin{array}{c}\text { Overall Rate } \\
(95 \% \mathrm{CI})\end{array}$ & $I^{2}(\%)$ & $\begin{array}{c}\text { Neonate Rate } \\
(95 \% \mathrm{CI})\end{array}$ & $I^{2}(\%)$ & $\begin{array}{c}\text { Infant Rate } \\
(95 \% \mathrm{Cl})\end{array}$ & $I^{2}(\%)$ & $\begin{array}{l}P \text { Value, } \\
\text { Neonate } \\
\text { vs Infant }\end{array}$ \\
\hline Technical complications & $19.0(12.0-27.0)$ & 48.9 & $29.0(17.0-41.0)$ & 7 & $10.0(0.0-27.0)$ & 45 & .07 \\
\hline Perioperative hemorrhage & $9.0(4.0-15.0)$ & 52 & $12.0(3.0-23.0)$ & 21 & $4.0(0.0-16.0)$ & 21 & .25 \\
\hline Perioperative ischemia & $1.0(0.0-2.0)$ & 0 & $3.0(0.0-10.0)$ & 0 & $0.0(0.0-2.0)$ & 0 & .03 \\
\hline Non-neurologic complications & $2.0(0.0-4.0)$ & 0 & $1.0(0.0-7.0)$ & 0 & $1.0(0.0-8.0)$ & 0 & 1 \\
\hline Technical mortality & $1.0(0.0-5.0)$ & 37 & $2.0(0.0-8.0)$ & 0 & $0.0(0.0-2.0)$ & 10 & .03 \\
\hline Complete occlusion & $56.0(46.0-66.0)$ & 49 & $59.0(45.0-73.0)$ & 0 & $56.0(17.0-91.0)$ & 74 & 1 \\
\hline All-cause mortality & $14.0(8.0-20.0)$ & 47 & $27.0(15.0-41.0)$ & 57 & $1.0(0.0-4.0)^{\prime}$ & 0 & $<.0001$ \\
\hline Poor neurologic outcome & $21.0(17.0-26.0)$ & 0 & $22.0(15.0-31.0)$ & 0 & $16.0(10.0-23.0)$ & 0 & .01 \\
\hline Good neurologic outcome & $62.0(57.0-67.0)$ & 3 & $48.0(35.0-62.0)$ & 50 & $77.0(70.0-84.0)$ & 0 & $<.0001$ \\
\hline
\end{tabular}




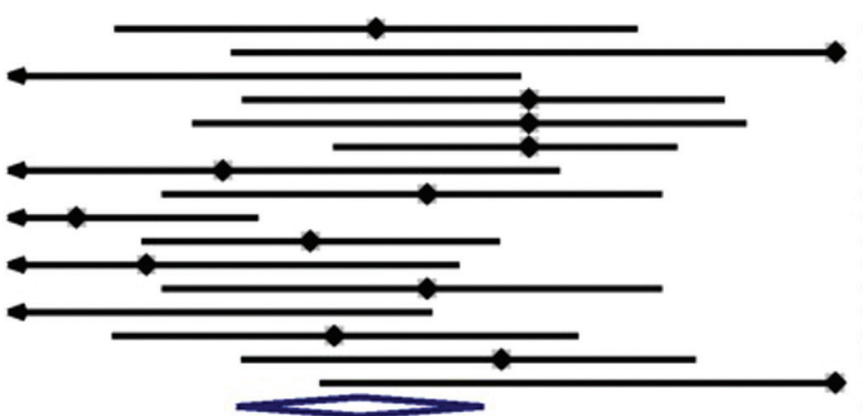

Overal

Geibprasert, Childs Nerr Syst, 2010

Chow, JNIS, 2015

Meila, Neuroradiology, 2012

Ellis, World Joumal of Radiology. 2012

Deloison, Utrasound Oostet Gynec. 2012

Berenstein, Neurosurgery, 2012

Moon, J Korean Neurosurg Society, 2011

Zuccaro, Childs Nerv Syst, 2010

Thiex, AJNR, 2010

Pongpech, Minim Invas Neurosurg, 2010

MoSweeney, Arch Child Dis, 2010

Heuer, Childs Nerv Syst. 2010

Hassan. Pediatr Neurosurg. 2010

Wong. J Perinatology, 2006

Lasłaunias, Neurosurgery, 2006

Gupta, J Neurosurgery, 2006

Jones, AJNR, 2002

Frawly. Arch Dis Child Fetal Neonatal Ed, 2002

Komiyama, hterventional Neuroradiology, 2001

Komiyama, hterventional Neuroradiology

Lylyk, J Neurosurg. 1993

Friedman, Pediatries, 1993

Casasco, Neurosurgery, 1991

Subtotal $\left(1^{*} 2=2.70 \%, p=0.42\right.$
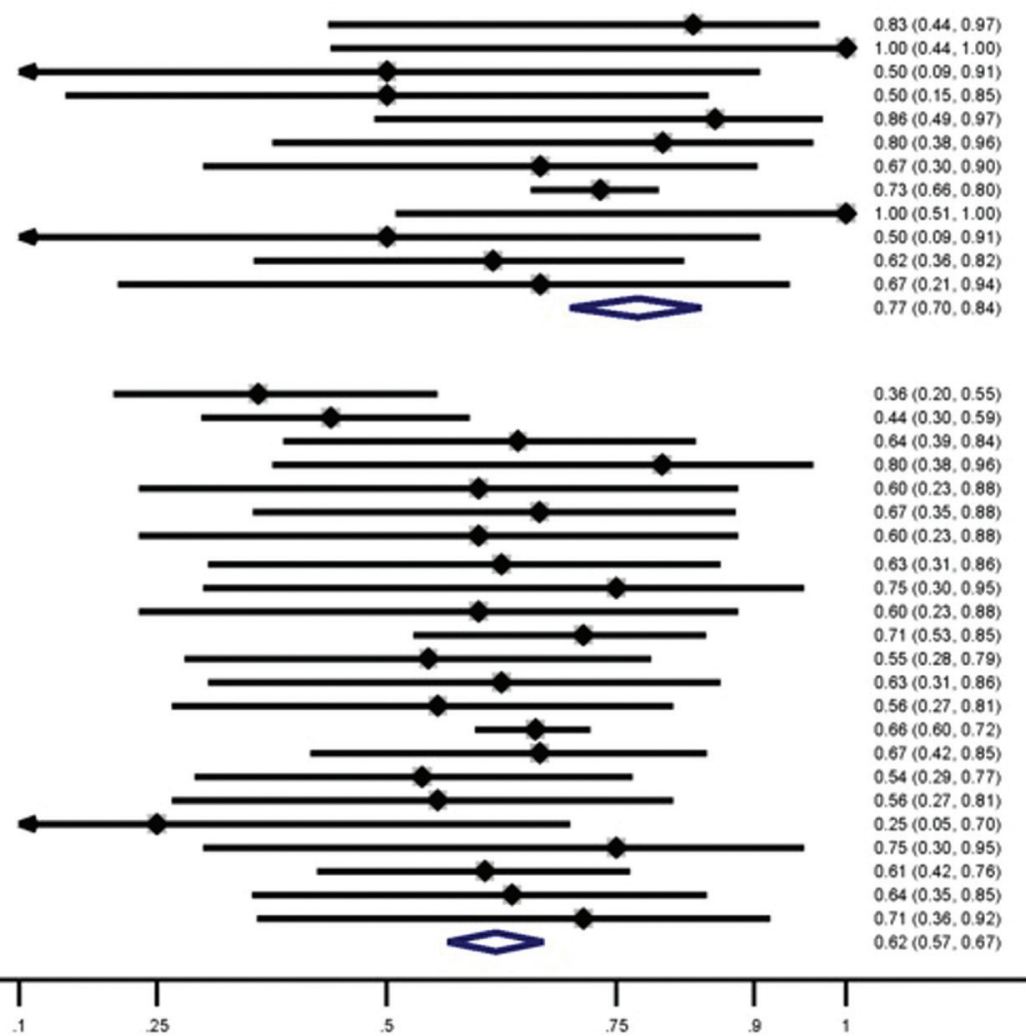

FIG 3. Forest plot for good neurologic outcome.

type VOGMs had a good neurologic outcome rate of 73.8\% (95\% CI, $59.0 \%-84.7 \%$ ) compared with $58.0 \%$ (95\% CI, $47.2 \%-$ $68.2 \%)$ for choroidal VOGMs $(P=.11)$. There was no association between a prenatal diagnosis and good neurologic outcome (66.7\%; 95\% CI, 53.7\%-77.5\% versus 63.1\%; 95\% CI, 50.9\%$73.8 \% ; P=.68)$.

There was a wide range in the follow-up times across studies, from 6 months to 6.8 years. The median follow-up time was 2 years, and the median age at which follow-up was performed was 2 years. Studies that reported a follow-up of $>2$ years had a good neurologic outcome rate of $60.3 \%$ (95\% CI, 55.1\%-65.3\%), while studies reporting a follow-up of $\leq 2$ years reported a good neurologic outcome rate of $64.6 \%$ (95\% CI, 54.6\%-73.4\%) $(P=.45)$.

\section{Study Heterogeneity}

When we considered all patients, $I^{2}$ values were $>50 \%$, indicating substantial heterogeneity for perioperative hemorrhage. $I^{2}$ values were $<50 \%$ for all other outcomes, indicating lack of substantial heterogeneity. When we considered neonates, $I^{2}$ values were $>50 \%$, indicating substantial heterogeneity for all-cause mortality. $I^{2}$ values were $<50 \%$ for all other outcomes, indicating a lack of substantial heterogeneity. When we considered infants, $I^{2}$ values were $>50 \%$, indicating substantial heterogeneity for complete occlusion. $I^{2}$ values were $<50 \%$ for all other outcomes, indicating a lack of substantial heterogeneity. These data are summarized in the Table.

\section{DISCUSSION}

Our study of $>500$ patients receiving endovascular treatment for VOGMs demonstrated many interesting findings. First, the most common presentation varied substantially by age of presentation as neonates were more likely to present with symptoms related to $\mathrm{CHF}$, while infants were more likely to present with head circumference increases or hydrocephalus. Given the poor natural history of VOGMs and the poor functional status of many patients 
who require treatment for these lesions, rates of good long-term neurologic outcomes were satisfactory at $>60 \%$. Patients who underwent treatment during the neonatal period were less likely to have a good neurologic outcome than those who were treated later in life, likely due to poorer cardiologic status at presentation and increased severity of disease. Perioperative complications were not negligible and were more frequent in neonates than in infants. However, procedure-related mortality rates were low. We found that patients who were treated according to the Bicêtre guidelines were more likely to experience good outcomes than those who were not; this finding highlights the importance of patient selection. Overall, our results suggest that endovascular treatment of VOGMs is generally safe and effective and can result in good long-term outcomes for patients in experienced centers. However, an emphasis on patient selection and timing is key.

As demonstrated in our study, the principal clinical manifestations of VOGMs are related to high-output cardiac failure or neurologic symptoms secondary to venous congestion and abnormal CSF flow. ${ }^{4,23,35,36} \mathrm{CHF}$ is the most common clinical presentation for neonates and is rarely the presenting symptom in infants or children because these patients often have fewer severe cardiac symptoms. In our study, approximately $90 \%$ of patients treated in the neonatal stage had CHF compared with $40 \%$ of patients treated in the infant stage. Many of the treated infants with CHF had medical stabilization of CHF during neonatal life with delay of treatment later in the first or second year of life. CHF can manifest itself on prenatal sonography or soon after birth, with symptoms ranging from mild overload to multisystem organ failure secondary to cardiogenic shock. On the contrary, patients with mild cardiac dysfunction may not have their VOGMs recognized until later in life when cerebral venous hypertension results in intracranial hypertension and subsequent macrocrania and hydrocephalus. As demonstrated in our study, $>50 \%$ of infants presented with macrocrania and nearly $40 \%$ presented with hydrocephalus. Other neurologic presentations, including seizure and intracranial hemorrhage, are present in roughly $20 \%$ and $10 \%$ of patients, respectively, with increased prevalence as age increases.

One of the important findings from our study was that studies that used a predefined selection criteria, the BNES, demonstrated higher rates of good neurologic outcome than those that did not. ${ }^{23}$ These findings highlight the importance of appropriate patient selection to ensure good neurologic outcomes. The BNES is a 21-point score that assesses a combination of cardiac, neurologic, respiratory, hepatic, and renal functions. ${ }^{51}$ Patients with a score of $\leq 8$ are thought to be poor candidates for endovascular treatment, and typically the recommendation is to withhold therapy from these patients. In the series of Lasjaunias et al, 30\% of all neonates and $17 \%$ of all infants had treatment withheld due to such low scores. A score between 8 and 12 indicates normal neurologic function but cardiac function that is refractory to medical management and, thus, emergency embolization, regardless of patient age. In the Lasjaunias series, only $25 \%$ of neonates met these criteria and underwent emergent embolization. ${ }^{51}$ However, in these patients, all-cause mortality was high and rates of good neurologic outcome were relatively low. Patients with a neonatal score of 13-21 could have embolization delayed until 3-5 months of age with stabilization of their cardiac function. This population comprised about two-thirds of patients in the series of Lasjaunias et al. ${ }^{51}$ Our study found that close to $50 \%$ of treated patients were treated in the neonatal stage, while only $5 \%$ of treated patients in the series of Lasjaunias et $\mathrm{al}^{23}$ were neonates.

The high proportion of neonates treated in our study implies that there may be a reflexive instinct to treat neonates presenting with VOGM at some centers without allowing a trial of medical stabilization. Such practice patterns may be detrimental to patients because treatment of neonates is associated with higher rates of technical complications and lower rates of good neurologic outcomes; and in select cases in which the neonate can be stabilized, delaying treatment for a few months may confer a benefit on the patient. ${ }^{23}$ Ultimately, due to the complex medical needs of this patient population, an argument can be made for centralization of medical and endovascular treatment for these patients.

Due to substantial heterogeneity and lack of specifics in reporting technical details of embolization procedures, we were unable to perform an extensive evaluation of the safety and efficacy of various techniques in the treatment of VOGMs. ${ }^{23}$ However, there are a few important implications from our study. First, as mentioned above, technical complications are more common in neonates than infants, likely due to a combination of smaller size, vascular fragility, and a more tenuous hemodynamic state. While most of the included studies predominantly treated patients transarterially, several series reported the exclusive use of transvenous or transtorcular techniques. ${ }^{27,37,45}$ Earlier series were more likely to report exclusive transvenous treatment or transtorcular embolization than more modern series however. In general, isolated transvenous treatment is thought to result in higher rates of technical complications due to higher rates of postoperative venous infarction, hemorrhage, and consumptive coagulopathy. ${ }^{19,23}$ Transtorcular embolization has become less and less common during the past decade due to extraordinarily high rates of such complications. Ultimately, treatment should be tailored to the angioarchitecture of the lesion and available routes for embolization. ${ }^{9}$ When we considered all patients, complete occlusion rates were approximately $60 \%$. Complete occlusion should not necessarily be the goal of VOGM embolization; rather, improvement in the physiologic and neurologic status of the patient should be the primary treatment goal.

\section{Limitations}

Our study has limitations. Ecologic bias (ie, comparisons are made across studies and not within studies), the presence of publication bias, and statistical heterogeneity are limitations that affect all meta-analyses. Our study also had limitations due to the methodologic limitations of included studies. All included studies were retrospective case series, which are prone to substantial selection bias. The use of the BNES in selecting patients also introduced selection bias because patients in whom treatment was thought to be futile were excluded in those studies. Little is known regarding the outcomes of patients who were untreated. It is also conceivable that with advancements in techniques and experience, many of the patients who were excluded on the basis of the BNES could now be treated. Many of the included studies had a small sample size and incomplete follow-up data. In some cases, 
definitions of outcomes (ie, good neurologic outcome, complete occlusion, technical versus all-cause mortality, and so forth) were not well-defined. In addition, many of the series in our analysis included cases collected during several years. It is possible that complication rates have improved because of increased operator experience and skill, improved patient selection, and improved devices and technology. We do not have enough data to determine clinical and angiographic outcomes by type of embolic agent used. Last, it is difficult to sort out short- and long-term morbidity and mortality related to the pathology of the underlying VOGM itself and of endovascular treatment.

\section{CONCLUSIONS}

Endovascular embolization of VOGMs can be successfully performed; however, complications are not negligible. Patient selection and timing of treatment are key to achieving good clinical outcomes. Further work is needed to provide improved outcomes associated with endovascular treatment of VOGMs. Large multiinstitutional registries may be helpful for collecting data in a standardized manner on the presentation and outcomes of these patients. Ultimately, these treatments are extremely challenging and should probably be reserved for centers with expertise in pediatric critical care and neurointervention.

\section{REFERENCES}

1. Raybaud CA, Strother CM, Hald JK. Aneurysms of the vein of Galen: embryonic considerations and anatomical features relating to the pathogenesis of the malformation. Neuroradiology 1989;31:109-28 CrossRef Medline

2. Moon JH, Cho WS, Kang HS, et al. Vein of Galen aneurysmal malformation: endovascular management of 6 cases in a single institute. J Korean Neurosurg Soc 2011;50:191-94 CrossRef Medline

3. Berenstein A, Fifi JT, Niimi Y, et al. Vein of Galen malformations in neonates: new management paradigms for improving outcomes. Neurosurgery 2012;70:1207-13; discussion 13-14 CrossRef Medline

4. Lasjaunias P, Hui F, Zerah M, et al. Cerebral arteriovenous malformations in children: management of 179 consecutive cases and review of the literature. Childs Nerv Syst 1995;11:66-79; discussion 79 CrossRef Medline

5. Frawley GP, Dargaville PA, Mitchell PJ, et al. Clinical course and medical management of neonates with severe cardiac failure related to vein of Galen malformation. Arch Dis Child Fetal Neonatal Ed 2002;87:F144-49 CrossRef Medline

6. Lin N, Smith ER, Scott RM, et al. Safety of neuroangiography and embolization in children: complication analysis of 697 consecutive procedures in 394 patients. J Neurosurg Pediatr 2015;16:432-38 CrossRef Medline

7. Kim DJ, Kim BM, Park KY, et al. Adjuvant coil assisted glue embolization of high flow vein of Galen aneurysmal shunt lesions in pediatric patients. Interv Neuroradiol 2015;21:315

8. Chow ML, Cooke DL, Fullerton HJ, et al. Radiological and clinical features of vein of Galen malformations. J Neurointerv Surg 2015;7: 443-48 CrossRef Medline

9. Meila D, Hannak R, Feldkamp A, et al. Vein of Galen aneurysmal malformation: combined transvenous and transarterial method using a "kissing microcatheter technique." Neuroradiology 2012;54: 51-59 CrossRef Medline

10. Ellis JA, Orr L, Ii PC, et al. Cognitive and functional status after vein of Galen aneurysmal malformation endovascular occlusion. World J Radiol 2012;4:83-89 CrossRef Medline

11. Deloison B, Chalouhi GE, Sonigo P, et al. Hidden mortality of prenatally diagnosed vein of Galen aneurysmal malformation: retro- spective study and review of the literature. Ultrasound Obstet Gynecol 2012;40:652-58 CrossRef Medline

12. Li AH, Armstrong D, terBrugge KG. Endovascular treatment of vein of Galen aneurysmal malformation: management strategy and 21year experience in Toronto. J Neurosurg Pediatr 2011;7:3-10 CrossRef Medline

13. Zuccaro G, Argañaraz R, Villasante F, et al. Neurosurgical vascular malformations in children under 1 year of age. Childs Nerv Syst 2010;26:1381-94 CrossRef Medline

14. Thiex R, Williams A, Smith E, et al. The use of Onyx for embolization of central nervous system arteriovenous lesions in pediatric patients. AJNR Am J Neuroradiol 2010;31:112-20 CrossRef Medline

15. Pongpech S, Aurboonyawat T, Visudibhan A, et al. Endovascular management in children with vein of Galen aneurysmal malformation. Minim Invasive Neurosurg 2010;53:169-74 CrossRef Medline

16. McSweeney N, Brew S, Bhate S, et al. Management and outcome of vein of Galen malformation. Arch Dis Child 2010;95:903-09 CrossRef Medline

17. Heuer GG, Gabel B, Beslow LA, et al. Diagnosis and treatment of vein of Galen aneurysmal malformations. Childs Nerv Syst 2010;26: 879-87 CrossRef Medline

18. Hassan T, Nassar M, Elghandour M. Vein of Galen aneurysms: presentation and endovascular management. Pediatr Neurosurg 2010; 46:427-34 CrossRef Medline

19. Geibprasert S, Krings T, Armstrong D, et al. Predicting factors for the follow-up outcome and management decisions in vein of Galen aneurysmal malformations. Childs Nerv Syst 2010;26:35-46 CrossRef Medline

20. Berenstein A, Ortiz R, Niimi Y, et al. Endovascular management of arteriovenous malformations and other intracranial arteriovenous shunts in neonates, infants, and children. Childs Nerv Syst 2010;26: 1345-58 CrossRef Medline

21. Staberg M, Jonsbo F. Vein of Galen aneurysm (VGA) diagnosed in the perinatal period: a retrospective assessment [in Danish]. Ugeskr Laeger 2007;169:3190-93 Medline

22. Wong FY, Mitchell PJ, Tress BM, et al. Hemodynamic disturbances associated with endovascular embolization in newborn infants with vein of Galen malformation. J Perinatol 2006;26:273-78 CrossRef Medline

23. Lasjaunias PL, Chng SM, Sachet M, et al. The management of vein of Galen aneurysmal malformations. Neurosurgery 2006;59(5 suppl 3): S184-94; discussion S3-13 Medline

24. Gupta AK, Rao VR, Varma DR, et al. Evaluation, management, and long-term follow up of vein of Galen malformations. J Neurosurg 2006;105:26-33 CrossRef Medline

25. Fullerton HJ, Aminoff AR, Ferriero DM, et al. Neurodevelopmental outcome after endovascular treatment of vein of Galen malformations. Neurology 2003;61:1386-90 CrossRef Medline

26. Jones BV, Ball WS, Tomsick TA, et al. Vein of Galen aneurysmal malformation: diagnosis and treatment of 13 children with extended clinical follow-up. AJNR Am J Neuroradiol 2002;23:1717-24 Medline

27. Frawley GP, Dargaville PA, Mitchell PJ, et al. Clinical course and medical management of neonates with severe cardiac failure related to vein of Galen malformation. Arch Dis Child Fetal Neonatal Ed 2002;87:F144-49 CrossRef Medline

28. Chevret L, Durand P, Alvarez H, et al. Severe cardiac failure in newborns with VGAM: prognosis significance of hemodynamic parameters in neonates presenting with severe heart failure owing to vein of Galen arteriovenous malformation. J Intensive Care Med 2002;28: 1126-30 CrossRef Medline

29. Mitchell PJ, Rosenfeld JV, Dargaville P, et al. Endovascular management of vein of Galen aneurysmal malformations presenting in the neonatal period. AJNR Am J Neuroradiol 2001;22:1403-09 Medline

30. Komiyama $M$, Nakajima $H$, Nishikawa $M$, et al. Vein of Galen aneurysms: experience with eleven cases. Interv Neuroradiol 2001; 7(suppl 1):99-103 CrossRef Medline

31. Ito O, Goto K, Ogata N, et al. Selection of endovascular approach of 
vein of Galen aneurysmal malformation. Interv Neuroradiol 2001; 7(suppl 1):187-92 CrossRef Medline

32. Meyers PM, Halbach VV, Phatouros CP, et al. Hemorrhagic complications in vein of Galen malformations. Ann Neurol 2000;47:748-55 Medline

33. Halbach VV, Dowd CF, Higashida RT, et al. Endovascular treatment of mural-type vein of Galen malformations. J Neurosurg 1998;89: 74-80 CrossRef Medline

34. Borthne A, Carteret M, Baraton J, et al. Vein of Galen vascular malformations in infants: clinical, radiological and therapeutic aspect. Eur Radiol 1997;7:1252-58 CrossRef Medline

35. Lasjaunias PL, Alvarez H, Rodesch G, et al. Aneurysmal malformations of the vein of Galen: follow-up of 120 children treated between 1984 and 1994. Interv Neuroradiol 1996;2:15-26 CrossRef Medline

36. Rodesch G, Hui F, Alvarez H, et al. Prognosis of antenatally diagnosed vein of Galen aneurysmal malformations. Childs Nerv Syst 1994;10:79-83 CrossRef Medline

37. Lylyk P, Viñuela F, Dion JE, et al. Therapeutic alternatives for vein of Galen vascular malformations. J Neurosurg 1993;78: 438-45 CrossRef Medline

38. Friedman DM, Verma R, Madrid M, et al. Recent improvement in outcome using transcatheter embolization techniques for neonatal aneurysmal malformations of the vein of Galen. Pediatrics 1993;91: 583-86 Medline

39. Lasjaunias P, Garcia-Monaco R, Rodesch G, et al. Vein of Galen malformation: endovascular management of 43 cases. Childs Nerv Syst 1991;7:360-67 CrossRef Medline

40. Garcia-Monaco R, De Victor D, Mann C, et al. Congestive cardiac manifestations from cerebrocranial arteriovenous shunts: endovascular management in 30 children. Childs Nerv Syst 1991;7:48-52 CrossRef Medline

41. Friedman DM, Madrid M, Berenstein A, et al. Neonatal vein of Galen malformations: experience in developing a multidisciplinary ap- proach using an embolization treatment protocol. Clin Pediatr (Phila) 1991;30:621-29 CrossRef Medline

42. Casasco A, Lylyk P, Hodes JE, et al. Percutaneous transvenous catheterization and embolization of vein of Galen aneurysms. Neurosurgery 1991;28:260-66 CrossRef Medline

43. Ciricillo SF, Edwards MS, Schmidt KG, et al. Interventional neuroradiological management of vein of Galen malformations in the neonate. Neurosurgery 1990;27:22-27; discussion 27-28 CrossRef Medline

44. Lasjaunias P, Rodesch G, Terbrugge K, et al. Vein of Galen aneurysmal malformations: report of 36 cases managed between 1982 and 1988. Acta Neurochir (Wien) 1989;99:26-37 CrossRef Medline

45. Hanner JS, Quisling RG, Mickle JP, et al. Gianturco coil embolization of vein of Galen aneurysms: technical aspects. Radiographics 1988;8:935-46 CrossRef Medline

46. Johnston IH, Whittle IR, Besser M, et al. Vein of Galen malformation: diagnosis and management. Neurosurgery 1987; 20:747-58 CrossRef Medline

47. Burrows PE, Lasjaunias PL, Ter Brugge KG, et al. Urgent and emergent embolization of lesions of the head and neck in children: indications and results. Pediatrics 1987;80:386-94 Medline

48. Deeks JJ, Dinnes J, D’Amico R, et al; International Stroke Trial Collaborative Group; European Carotid Surgery Trial Collaborative Group. Evaluating non-randomised intervention studies. Health Technol Asses 2003;7:iii-x, 1-173 Medline

49. DerSimonian R, Laird N. Meta-analysis in clinical trials. Control Clin Trials 1986;7:177-88 CrossRef Medline

50. Higgins JP, Thompson SG, Deeks JJ, et al. Measuring inconsistency in meta-analyses. BMJ 2003;327:557-60 CrossRef Medline

51. Alvarez H, Garcia Monaco R, Rodesch G, et al. Vein of Galen aneurysmal malformations. Neuroimaging Clin N Am 2007;17:189-206 CrossRef Medline 